\title{
Human Health Implication of 900MHz and 1800MHz Mobile Phones
}

\author{
Kasumawati Lias $^{\# 1}$, Dayang Azra Awang Mat ${ }^{\# 2}$, Kuryati Kipli ${ }^{\# 3}$, Ade Syaheda Wani Marzuki ${ }^{\# 4}$

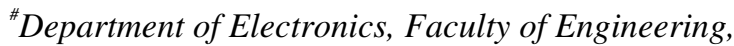 \\ Universiti Malaysia Sarawak, Sarawak, 94300 Kota Samarahan, Sarawak, Malaysia. \\ ${ }^{1} 1$ kasumawati@feng.unimas.my \\ 2amdazra@feng.unimas.my \\ ${ }^{3}$ kkuryati@feng.unimas.my \\ maswani@feng.unimas.my
}

\begin{abstract}
In recent years, there has been increasing public concern about the health implication of Electromagnetic (EM) wave exposures due to the mobile phone. For this reason, various public organizations in the world have been established safety guidelines. This paper focused on the investigation or study of human health effect that cause by the used of $900 \mathrm{MHz}$ and $1800 \mathrm{MHz}$ mobile phones. For the purpose of the assessment, FiniteDifference Time Domain (FDTD) is used to find the Specific Absorption Rate (SAR) value of mobile phones that absorbed into human head. The minimum SAR value stated by International Commission on Non-Ionization Radiation Protection (ICNIRP) is $4 \mathrm{~W} / \mathrm{kg}$. When the limit is exceeds, it produces human health effects where it can caused reverse cell membrane polarity, alter brain waves and brain chemistry and damage DNA. This leads to cancer and memory loss. However, mobile phones are designed with low power and operate at high frequency where the value of SAR is lower than the limit that stated by ICNIRP. Other temporary biological or potential human health effects produce by mobile phones are heating, headache, fuzziness, fatigue and nausea. By the way, further studies or researches are needed in order to draw more complete picture of health risks that cause by the use of mobile phones.
\end{abstract}

Keywords - Electromagnetic wave, Specific Absorption Rate,Finite-Different Time Domain, Potential Health Effect, Adverse Health Effect

\section{INTRODUCTION}

Mobile phone also known as cellular phone which is short range, portable electronic device used for voice or data communication over a network. According to the research, by the year of 2007, the total number of mobile phone subscriptions in the world had reached about 3.3 billion or equivalent to half of the human population. The increasing number of mobile phones users had contributed to health issues concern among the public. There are numerous researches and studies have been carried out onto the adverse health effects of electromagnetic radiation exposure [1-4].

A fundamental parameter for discussing the health risks of electromagnetic field power absorption in the human head is the specific absorption rate (SAR) $[5,6]$. SAR is a measurement of the rate at which radio frequency $(\mathrm{RF})$ energy is absorbed by the body when exposed to radio frequency electromagnetic field over a given period of time. It also can be defined through mathematical approach as the equation 1.1 below with the units Watts per kilogram, $\mathrm{W} / \mathrm{kg}[7,8]$.

$$
S A R=\sigma E^{2} / \rho
$$

Where $\sigma$ the conductivity of the tissue, $\mathrm{E}$ is is the electric field density in the tissue and $\rho$ is the density of the tissue.

\section{METHODOLOGY}

This paper mainly investigate human health implication by the used of $900 \mathrm{MHz}$ and $1800 \mathrm{MHz}$ mobile phone. Finite Difference Time Domain (FDTD) is used to simulate the modeling. There are three option of SAR value in FDTD. They are SAR distribution, SAR in $1 \mathrm{~g}$ weight and SAR $10 \mathrm{~g}$ weight. This investigation covered SAR distribution only for a model of human head. SAR distribution was calculated for the distance between the monopole antenna and the head in the range of $10 \mathrm{~mm}$. The frequency used for the simulation was chosen to be $900 \mathrm{MHz}$ and $1800 \mathrm{MHz}$ with mobile phone radiated power of $0.6 \mathrm{~W}$.

First, the mobile phone is modelled with the guide of FDTD manual. Then, it is simulate in order to get the radiation pattern of the $900 \mathrm{MHz}$ and $1800 \mathrm{MHz}$ mobile phone. After that, human head with the attachment of mobile phone is created for the next simulation purpose. The radiation pattern of mobile 